The reviewer regrets the asperity of his criticisms. Let it be granted that the handbook is not written for pedants like himself. It is written for busy men. There is the more need, therefore, for the arrangement to be logical and readily understood, and for language to be clear and without ambiguity. (What is meant, for instance, by the sentence in 2.2, that a Family Practitioner Committee 'has the power to assign a patient to a doctor whether he agrees or not'? Who is he, the doctor or the patient?) The Handbook is now on public sale, and we would wish it well if it can bridge the gap, in understanding and confidence, which seems to be widening, between the profession and the public. Fortunately it does not stand alone: indeed, the literature of medical ethics may soon call for the pruning knife. And when shall we move on to the next step, to educate the lay public in the ethics of patient practice? There is a mutuality of expectation in ethics; so far, we seem to ignore it.

G R DUNSTAN

\section{The Ethics of Resource Allocation in Health Care}

\author{
K M Boyd \\ Edinburgh University Press, pp I52, \\ $£ 5 . \infty$.
}

In the confident 'sixties it seemed to many people that social scientists had the tools to approach and solve social problems as though they were technical problems. Reductionist analysis of a social problem by econometricians and other social scientists would, it appeared, provide the solutions to problems such as the inner cities or the cycle of deprivation or resource allocation. Government and the development of public services were to be conducted with management tools, even the metaphor implied social engineering such as planned programme budgetting, and difficult decisions were to be made by cost-benefit analysis and cost-effectiveness studies. This rational, engineering, approach failed because the problems which these techniques were used to solve were of a different nature from the problems experienced by the Ford Motor Company or Glacier Metal for which they had been developed. There were certain similarities but the problems of the public services had an ethical dimension which the the problems of industry lacked.

As this is increasingly appreciated the ethical aspects of resource allocation are once more receiving proper attention and this book will make a useful contribution to the debate. It is an expression - neither the term 'record', nor 'summary', nor 'report' is adequate - of the thoughts of a group of 14 people, comprising both health professionals and lay members, which debated this issue for two years under the aegis of the Edinburgh Medical Group. I use the word 'expression' because my impression is that the editor, who was the Group's Research Fellow in 1975, has managed to write a synthesis not only of what was said and concluded but of what was felt and implied by the members of the discussion group: a rare achievement.

There are five chapters. The first sets out the problem, listing the options facing health service managers, and summarises two principal theories of distributive justice - utilitarianism and John Rawl's theory. The second is a record of the group's consideration of certain issues, to illustrate their way of working and their principal conclusions. The third chapter sets the issues in a historical perspective and the fourth complements this by looking at the issues from four perspectives - 'ecological and epidemiological', typified by McKeown; 'clinical'; 'administrative', a very pragmatic and business-like perspective; and an 'egalitarian', or socialist perspective. The final chapter attempts to summarise the tension which exists between the technical and political approaches to resource allocation. The book also has two long appendices on health econometrics and on decision making in the NHS in Scotland.

I would have liked much more discussion on the conclusion on 'which there was least agreement' - that the order of priorities for resource allocation should be prevention then cure and finally rehabilitation. I would also have liked to see a greater proportion of the book devoted to a consideration of the comparison of different client groups, for example the comparison of the needs of old people with the needs of those who are mentally ill.

The reader who seeks answers will be disappointed because the book does not give any answers. What it does do, and perhaps all that it is possible for any book to do, is to pose the right questions. It emphasises the moral dimension of decision making and the fact that moral enquiry has an essential part to play in the political or professional approach to resource allocation.

This is a very useful book.

J A MUIR GRAY
Encyclopedia of Bioethics Warren T Reich (Editor-in-Chief) Macmillan and Free Press 1978. 4 Vols pp I, $800, \$ 200$

How can one possibly review a four vol $\overrightarrow{\overline{\vec{\nu}}}$ ume work containing 315 separate arti cles? Inevitably any assessment must beㄷㅇ in terms of overall impression togethe $\overline{5}$ with a somewhat random sampling of specific contributions. An encyclopedia is, after all, essentially a work of refer ence to be turned to at times of need. The test of its usefulness must be the extent to which it seems likely to fulfi the needs of various groups interesteow in 'bioethics' (a term defined in the Editor's Introduction as 'the systematiç study, in the light of moral values ands principles, of human conduct in the area of the life sciences and health care').

The first overall impression given by this work is lavishness in production? Large, clear type, high quality paper and excellent binding make the Encyc $\int$ lopedia into a durable and easily reađe reference work. Having decided on such an expensive production, the publishers are to be complimented or their attention to detail. (For example $\vec{e}$ the volumes lie open flat, allowige quick reference to different pages. $A$ second immediate impression is taf this work has been planned primarilu with an American readership in mind. The term 'bioethics' conveyष్రి this at once, of course, but, in addition, the editorship, consisting of one editor-in-chief and five associate editors, is exclusively American. Admittedly such a complex undertaking could hardly have been. completed so quickly without this national concentration and the 600 strong Editorial Advisory Board doeș contain 18 members from other coun? tries. Nevertheless, there is a dange that the sudden flowering of writing and $B$ research in this subject area in the USA may exert an undue influence on the language and theoretical development? of bioethics in the rest of the world An example of this danger may bo found in the remarkably comprehensive section on the history of medicat ethics ( 130 pages of text, spanning the history in primitive societies, Near and Middle East and Africa South and East Asia, Europe and the Americas). Although the editors have brought together a commendably wide range of authors in the African, Asian, and Near and Mid dle East sections they rely to a surpris ing extent on American scholars in th section on the European and Americaro 
history. The danger of national bias is seen more clearly in the various entries on health and health care. Injustice in health care provision is widely acknowledged to be a major problem in American medicine, yet all the authors in this vital section of the encyclopedia are based in the USA! Certainly, most of the entries are well balanced (and even a little critical), but they lack the cutting edge which might have been provided by European or Third World authors. (Ivan Illich's searing attacks on medicine's 'expropriation of health' gain not even a mention in this whole section, nor do Vicente Navarro's analyses of the capitalist underpinning of American medicine).

First impressions, then, are of a well produced but perhaps somewhat myopic reference work. But such initial reactions can be misleading and unjust. How useful are the volumes to people who need readily accessible information on their subject area? In his Introduction the Editor-in-Chief envisages four groups of readers: teachers and their students (in the relevant subjects); journalists and writers; health professionals; policy makers and implementers. The first group of readers is difficult to delineate precisely, but let us suppose that they are medical teachers with a concern for the ethical aspects of their specialities. Here a little patience will be necessary. There are no entries or cross references under psychiatry, obstetrics, paediatrics, geriatrics (but a cross reference from psychoanalysis to 'dynamic therapies' will be found). The specialist must think of his patients and seek entries under mental health, infants (not birth), children, aging and the aged, etc. (An exception is the surgeon, who is provided with an entry under surgery, though it is surprisingly brief.) What of the teacher or student in medicine who wants to check up on some ethical or philosophical concepts? Here the entry on ethics will serve him excellently. Twelve separate articles (whose authors include $\mathbf{R} \mathbf{M}$ Hare, Joseph Fletcher and Philippa Foot) lay the groundwork well, but beyond this, the index will be essential, otherwise readers may be left unaware of important entries (eg on Pragmatism, Double Effect, and Reductionism).

The second group of readers (journalists, non-scholarly writers) will surely be pleased with the extensive entries on death, sex, abortion, euthanasia, etc. These areas of the subject, so prominent in the public mind, are explored in an extensive and scholarly manner. The third group (health professionals) are somewhat unevenly catered for. There are only a few articles about the 'paramedical' professions. Social work appears under medical social work. There are no entries for clinical psychology, occupational therapy, physiotherapy, speech therapy, etc. Nursing is quite extensively discussed, though little is said about psychiatric nursing. Chaplaincy is cross-referenced to 'pastoral ministry', but this heading is rather misleading since the article discusses many different aspects of the interaction between medicine and the clergy. So far as the theoretical background of professional work is concerned, religion is given a remarkably generous treatment in comparison with (say) psychology or sociology. The editors see religious traditions as an important influence on ethics and have commissioned articles on Buddhism, Confucianism, Eastern Orthodox Christianity, Hinduism, Islam, Judaism, Protestantism, Roman Catholicism and Taoism. To a 'religious professional' like myself such a range is richness indeed - but will such detail be seen as relevant by other health care professions, many of whom regard religion as of no consequence in moral issues? Perhaps in this area the editors feel they have an educational or even evangelistic task to exercise.
The fourth group of readers - the $\stackrel{\overparen{D}}{\stackrel{1}{2}}$ policy makers (politicians) and policy implementers (judges, civil servants, administrators) - could gain a lot from ? the Encyclopedia, if they can be per- $\vec{F}$ suaded to see its relevance. I cannot $\stackrel{\text { ? }}{+}$ imagine many of this group turning to을 the more theoretical entries on ethics, 흠 religion, the history of medical ethics or $\overline{\bar{s}}$ the philosophy of medicine. But they $\overparen{\nabla}$ might well want to discover a summary of scholarship on contemporary issues $\omega$ of debate, eg fetal research, $\overrightarrow{0}$ psychosurgery, kidney dialysis, heart transplantation. In this they will be well $\vec{\omega}$ served. Obviously the quality of entries varies a little, but from them all we gain $\overline{3}$ a well-researched, balanced and clearly summarised survey of the contem- $\omega$ porary debate.

How useful then is the Encyclopedia? $\overrightarrow{\mathrm{C}}$ It is not easy to come to any conclusive answer to this question, for, it depends 0 very much on the use one has in mind. For the busy practitioner (in medicine $\vec{c}$ or other health care professions) it is $\mathbb{D}$ probably too detailed, too theoretical $-\frac{\vec{D}}{D}$ and too expensive! Here it compares $\overline{3}$ unfavourably with the compact and economically produced Dictionary of Medical Ethics. The specialist student $8 \mathrm{f} \overrightarrow{0}$ this area of ethics, on the other hand, will find it an indispensable reference work, for it contains a truly impressife range of scholarship and as well as herpful lists of bibliographical references. $\bar{D}$ The final test of the Encyclopedia's usefulness will be the extent to which it $\stackrel{\mathbb{Q}}{\mathcal{Q}}$ becomes a reference work for educators $\overrightarrow{\bar{B}}$

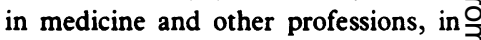
specialities other than ethics. These volumes could be a valuable educational resource for them. I trust that the omissions and occasional biasses I have already noted will not obscure the value $\overparen{D}$ of this work to all professional educators $\frac{0}{3}$ in health care, who are willing to explore with their students the ethicalo implications of their speciality.

A V CAMPBELI 의

.

